\title{
East Coker
}

En mi comienzo está mi fin. En sucesión

las casas se levantan y caen, se derumban, se extienden

se trasladan, destruyen, restauran, o en su sitio

un campo abierto surge, o un taller o un sendero.

Vieja piedra para nuevo edificio, vieja leña para nuevas hogueras

hogueras viejas, cenizas, y cenizas para la tierra

que es ya carne, piel y heces.

Huesos del hombre y de la bestia, maíz y hoja.

Las casas viven y mueren: hay una hora para edificar

y una hora para vivir y para generar

$y$ una hora para que el viento rompa el flojo vidrio

y sacuda el friso de madera donde trota el ratón campesino

y sacuda el tapiz desgarrado en el que está tejido

un silencioso lema.

En mi comienzo está mi fin. Cae ahora la luz

a través del baldío, dejando el callejón profundo

cerrado por las ramas, postigos que lo oscurecen en la tarde,

donde tú te reclinas contra un ribazo mientras un carro pasa,

y el hondo callejón insiste en dirección

hacia la aldea, hipnotizado por el calor eléctrico. 
En el cálido vaho, la bochornosa luz es absorbida, no refractada por la piedra grisácea.

Duermen las dalias en el vacío silencio esperan por el temprano buho.

En ese campo abierto

si no te acercas demasiado, si no te acercas demasiado, en una noche de verano, puedes oír la música de la apagada flauta y el pequeño tambor y observarlos danzar en redor de la hoguera asociación de hombre y de mujer en danza que significa matrimonio un sacramento dignificado y cómodo. Dos y dos, conjunción necesaria, tomados de la mano, o del brazo presagio de concordia. Girando alrededor del fuego brincando entre las llamas, o reunidos en corros; rústicamente serios o en rústica algazara levantando pesados pies en zapatones rústicos; pies de tierra, de gleba, levantados en campesino gozo gozo de los que yacen ha mucho bajo tierra nutriendo los maizales. Manteniendo el compás manteniendo el ritmo de su danza y el de su vida, en las épocas de vida. El compás de estaciones y de constelaciones el compás del ordeñe y el compás de cosechas el compás de la cópula del hombre y la mujer y la de las bestias. Los pies se levantan y caen. El comer y el beber. Estiércol y muerte. Amanecer apunta, y otro día se apresta para calma y calor. Mar afuera, el viento de la aurora lo arruga y se desliza. Estoy aquí o allá, o en cualquier otra parte. En mi comienzo. 
II

¿Qué hace el noviembre último con el disturbio de la primavera y las criaturas del calor estival y los copos de nieve, crujientes bajo el pie $y$ las malvas que aspiran, demasiado alto, a tornar rojo en gris, y se desploman? ¿Son las últimas rosas, llenas de nieve tempranera? Rueda el trueno junto a estrellas rodantes y simula los carros triunfales desplegados en guerras consteladas:

Escorpión combate contra el Sol hasta que el Sol y la Luna descienden los Cometas sollozan y los Leonidas vuelan batiendo en caza los cielos y llanuras arremolinados en un vórtice que llevará al mundo al fuego destructivo que arde antes que el casco polar reine.

Esta era una manera de decirlo, no muy satisfactoria; estudio, perifrástico, de moda poética gastada, que lo deja a uno quieto, en lucha insoportable con palabras y significaciones. No importa la poesía. No era (para recomenzar) to que uno había esperado. ¿Cuánto debió valer lo que uno había esperado largamente, en larga expectación calmosa, de la otoñal serenidad, y la sapiencia de los años? ¿Es que nos habían engañado a nosotros, o a sí mismos, los mayores, los de voz apagada, al legarnos tan sólo un recibo doloso?

La serenidad, nada más que un deliberado embotamiento; la sapiencia, tan sólo el conocer secretos muertos 
inútiles para las tinieblas en que escrutan, o de las que retornan sus pupilas. Hay, creemos, a lo sumo, solamente un valor limitado en el conocimiento basado en la experiencia. El conocimiento impone un molde, y falsifica, pues el molde se renueva a cada instante $y$ cada instante es una nueva y enfadosa valuación de cuanto habíamos sido. Unicamente somos engañados por lo que engañado, ya no puede dañar.

En la mitad, no sólo en la mitad de nuestra ruta sino en todo el camino, en una selva oscura, en la maleza al borde de un pantano, donde el paso no es firme y amenazados por monstruos, y luces fantasiosas arriesgamos devenir hechizados. Que no oiga de la sabiduría de los viejos; mejor de su locura, de su temor al miedo y frenesí, de su temor de poseer o de pertenecer a algún otro, o a otros, o a Dios. La única sabiduría que podemos aspirar a adquirir es la sabiduría de la humildad, la humildad es infinita. Todas las casas yacen ahora bajo el mar. Todos los danzarines yacen bajo la loma, ahora.

Oh, la oscura tiniebla. Todos ellos penetran la tiniebla el vacío espacio intraestelar, vacío en el vacío.

Capitanes, banqueros, eminentes hombres de letras, mecenas generosos, gobernantes, preclaros estadistas prominentes funcionarios públicos, presidentes de muchos comités magnates industriales, pequeños contratistas, todos irán a las tinieblas y a las tinieblas el Sol y la Luna, y el Almanaque de Gotha y la Gaceta de la Bolsa, la Guía de Directorios y fríos estarán los sentidos, y perdido el motivo de acción. 
$Y$ con ellos iremos nosotros, en el silente funeral

funeral de ninguno, pues a nadie enterramos.

Yo le dije a mi alma, quedă quieta, y que venga hacia ti la tiniebla que será la tiniebla de Dios. Como cuando en un teatro

se extinguen las luces para cambiar la escena

con un hueco rumor de aleteos, con un movimiento de tinieblas

dentro de las tinieblas

y sabemos que las colinas y los árboles, y aquel distante panorama

y la audaz, imponente fachada son recogidos prestamente

o como cuando un tren subterráneo se detiene en el túnel

por demasiado tiempo entre dos estaciones

y la charla se anima, y decae lentamente en silencio

y tú ves que se ahonda la vacuidad mental detrás de cada rostro

dejando solamente el creciente terror

de no tener ya nada en qué pensar;

o cuando, bajo éter, el cerebro es consciente, mas consciente de nada.

Yo le dije a mi alma, queda quieta, y espera sin esperanza

pues esperar sería esperar el error; espera sin amor,

pues amar sería amar el error; aún existe la fe

pero la fe, el amor y la esperanza están sólo en la espera.

Espera sin pensar, pues no estás lista aún para la reflexión;

de este modo, serán luz las tinieblas, y la quietud, la danza.

Murmullo de corrientes e invernales relámpagos

el tomillo silvestre, no visto, y la silvestre fresa,

la risa en el jardín resonaba como éxtasis

no perdido aún, mas requiriendo, indicando la agonía

de muerte y nacimiento.

Dices que yo repito

algo que antes dijera. Lo diré otra vez.

¿Otra vez lo diré? Para llegar allá

allá donde tú estás, para partir de donde tú no estás, 
has de ir por un camino donde no existe el éxtasis para alcanzar a lo que tú no sabes, has de ir por un camino que es el de la ignorancia para que tú poseas lo que tú no posees has de ir por el camino de la desposesión para que llegues a donde tú no estás has de ir por un camino en que no estás y lo que tú no sabes es lo único que sabes y'lo que tienes es lo que tú no tienes y donde estás es donde tú no estás.

IV

Su bisturí dispone el herido cirujano y con él examina la parte que tortura; nosotros percibimos, en su sangrienta mano la aguda compasión del arte de quien cura resolviendo el enigma de la temperatura.

Nuestra salud es tan sólo nuestro mal si obedecemos a la "nurse" muriente; no complacer es su tarea habitual mas recordarnos nuestro, y de Adán, origen maldiciente y que para sanarnos debemos devenir más dolientes.

El mundo entero es nuestro hospital nuestra herencia del magnate arruinado donde nos moriremos, si nada hacemos mal, del absoluto y paternal cuidado que no nos dejará, sino que guiará por todos lados. 
Del pie a la rodilla sube el escalofrío, la fiebre canturrea en alambres mentales, si quiero estar caliente, debo soportar frío y tiritar en frígidos fuegos purgatoriales cuyas Llamas son rosas, y cuyo humo, zarzales.

Nuestra sola bebida, la sangre que gotea;

nuestro solo alimento, la carne ensangrentada, mas a pesar de ello, nos complace la idea de que somos sólida carne y sangre sustanciada y no obstante, otra vez, Viernes Santo esta fecha es llamada.

Así, acá estoy yo, a mitad de camino, habiendo pasado veinte años veinte años malgastados, años de "l'entre deux guerres" tratando de aprender a usar palabras, y cada tentativa es un comienzo enteramente nuevo, y una distinta clase de fracaso porque uno ha aprendido solamente a obtener lo mejor de las palabras para lo que ya uno no tiene que decir, o para el modo en que uno no está ya dispuesto a decirlo. Así, cada ventura es un nuevo comienzo, y una incursión en lo inarticulado con un equipo mísero, siempre deteriorándose en el usual desorden del sentir impreciso, tropa indisciplinada de emoción. Y lo que se conquiste por fuerza y sumisión, ya ha sido descubierto una, dos, varias veces, por hombres a los que uno desespera de emular, pero no es competencia, solamente la lucha por recobrar lo ya perdido $y$ encontrado, $y$ perdido otra vez, y otra vez: $y$ ahora en condiciones 
que parecen impropias. Pero quizá no haya ni ganancia ni pérdida. Para nosotros, sólo queda intentar. Lo demás no nos cuenta.

El hogar es el sitio de donde uno parte. A medida que envejecemos deviene extraño el mundo, y la figura más y más complicada con los vivos y muertos. No el intenso momento aislado, sin antes ni después, sino una vida entera, ardiendo en cada instante y no la vida de solamente un hombre sino de viejas piedras aún indescifradas.

Hay una hora para el anochecer bajo la luz de estrellas, una hora para el anochecer a la luz de la lámpara (anochecer con el álbum fotográfico) el amor está más cerca de sí mismo cuando de pronto cesa de importar. Los viejos deben ser exploradores de aquí o de allá, no importa el sitio nosotros debemos estar quietos y al mismo tiempo en movimiento hacia otra intensidad para ulterior unión, para una comunión más profunda a través del frío oscuro, y la vacía desolación, la ola llora, el viento llora, las vastas aguas del petrel y la marsopa. En mi fin está mi comienzo.

T. S. ELIOT. Tradujo Américo Barabino. 